\title{
An Analysis of Unsignalised Intersection Using aaSIDRA Software
}

\author{
Wan Al-Junaidi Bin Jamil ${ }^{1}$ and Wan Hashim Wan Ibrahim ${ }^{2}$
}

\begin{abstract}
This thesis discusses about the use of Akcelik \& Associates Signalised \& Unsignalised Intersection Design and Research Aid (aaSIDRA Intersection) Software in the analysis of unsignalised intersection in Sarawak, Malaysia. aaSIDRA Intersection software was used to analyse the data which were manually obtained through traffic volume study carried out at the two junctions during the morning peak period and also helps in producing the capacity and Level of Service of the intersection. Four parameters were analysed in this thesis: critical gap, follow-up time, proportion of heavy vehicles or motorcycles and total number of vehicles for each of the approaches of the intersection. Referring to the Highway Capacity Manual (HCM), these variable parameter values are determined and then the expected output of the aaSidra being used in the analysis of this study are average control delay, existing level of service, and capacity of the junction. Fixed values to be input into SIDRA Intersection are obtained from the traffic volume study. The input influences the value for the average control delay which assists in determining the Level of Service of the intersection. These output values are highly influenced by the respective input values. All factors analysed under four parameters to determine the level of service of the two junctions were contributing equally and correlates with each other and there was not one that exceeds the other factor. The critical factors affecting the level of service are critical gap and traffic volume.
\end{abstract}

Keywords: unsignalised, critical gap, follow-up time, control delay, level of service.

\section{INTRODUCTION}

$\mathrm{T}$

HE rapid development in Malaysia has brought an increase to the cost of living of the citizen. It influenced the travel pattern of the community from their origin to any destination. The development also affects the transportation system as shown by the annual increase in the number of vehicles on roads.

Chronic traffic jams can cause loose billions of hours and money. Carter and Robinson (1982) and McShane and Roess (1990) stated that it requires creating an efficient method to resolve traffic congestion and reducing the delay time [1]. Statistic shows that the number of vehicles has increased every year (Highway Planning Unit, 2008) [2]. Congestion has been a big problem with the increase in traffic volume. This traffic congestion occurs when a volume of traffic generates demand for space greater than the available road capacity. The intersection is a part of the road network besides roundabout. Thus, planning and constructing a better intersection is important to reduce traffic congestion and accidents. Unsignalised intersection is a common type of intersection that is used to control traffic movement. It plays an important role in determining the overall capacity of road networks. Currently, Malaysia is using its standard from Malaysian Highway Capacity Manual 2006 [3] which was adopted from the United States Highway Capacity Manual 1985 (U.S.HCM 1985) as the procedure to evaluate unsignalised intersections and known as Arahan Teknik (Jalan) 11/87 [6].

This study focuses on the Analysis Performance of Unsignalised Intersection using Akcelik \& Associates Signalised Intersection Design and Research Aid (aaSIDRA) Intersection. aaSIDRA ia a well-known software package that world widely used for intersection capacity, level of service and performance analysis. SIDRA intersection is one of SIDRA solutions software products owned by Akcelik and Associates Pty Ltd (Akcelik, 2000) [11]. The main purpose of this study is to analyse factor that affects the level of service of a junction.

The objectives of this study are:

i. To identify intersection to be studied.

ii. To determine the level of service at an unsignalised junction.

iii. To carry out capacity analysis for an unsignalised junction using aaSIDRA Intersection Version 5.1.

iv. To determine the sensitivity analysis of the input parameters .

\footnotetext{
${ }^{1}$ Wan Al-Junaidi Bin Jamil is a student from the Department of Civil Engineering, Faculty of Engineering, Universiti Malaysia Sarawak, 94300 Kota Samarahan, Sarawak, Malaysia.

${ }^{2}$ Wan Hashim is a Professor in the Deaprtment of Civil Engineering, Faculty of Engineering, Universiti Malaysia Sarawak, 94300 Kota Samarahan, Sarawak, Malaysia. (e-mail: wiwhashim@feng.unimas.my)
} 


\section{STUDY METHODOLOGY}

In this study, data collection was carried out at two unsignalised T-junctions, i.e. Jalan Datuk Mohammad Musa-Jalan Desa Ilmu as shown in Figure 1 and Jalan Datuk Mohammad Musa-Jalan Kuap as shown in Figure 2. The collected data were analysed using SIDRA Intersection software in order to determine critical factors affecting the level of service of a junction.

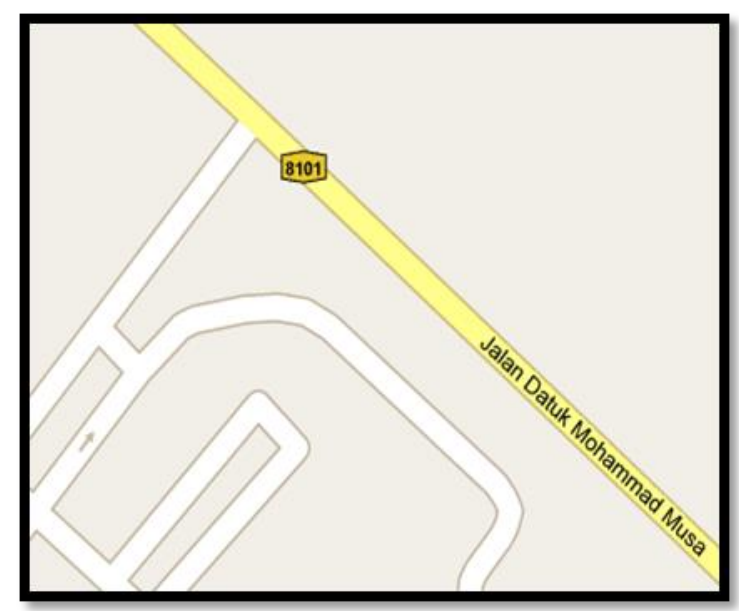

Figure 1: Unsignalized T-Junction of Jalan Datuk Mohammad Musa-Jalan Desa Ilmu

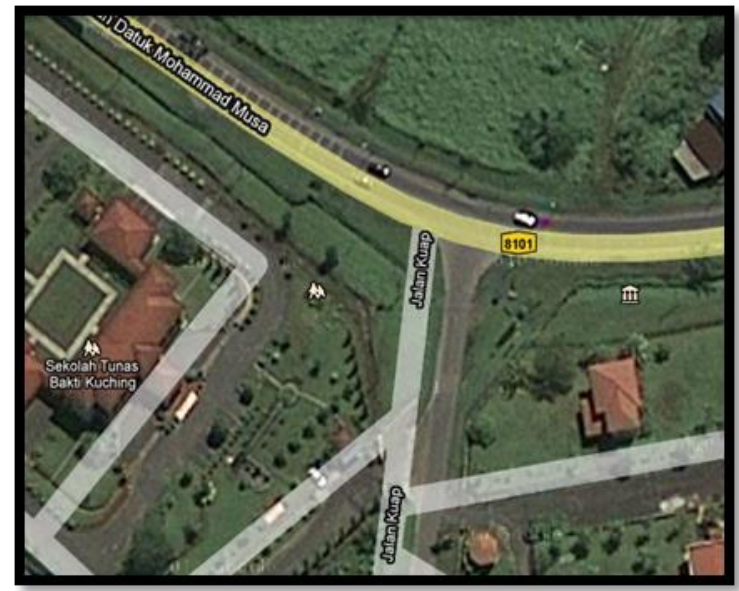

Figure 2: Unsignalised T-Junction of Jalan Datuk Mohammad Musa-Jalan Kuap

The selections of the study location are based on these criteria: unsignalised interection, the number of passing vehicles especially passenger's cars and motorcycle is high, the adequacy of a facility to accommodate high traffic volume and the high traffic volume resulting in congestion at peak hour. The site selected in this study is a junction. The location for this study is at a junction situated at major road Jalan Datuk Muhammad Musa into Jalan Desa Ilmu at Kota Samarahan area and major road of Jalan Datuk Muhammad Musa into minor road Jalan Kuap. The equipment that has been used during the field data collection includes walking wheel, stopwatch and also traffic counter.

In order to obtain the traffic flow during the peak hour, observation must be carried out during morning peak hour and also evening peak hour. The following should be considered while collecting the data: site characteristics of an intersection, traffic volume and vehicle classification based on Malaysian traffic characteristic as shown in Table 1. The traffic must be observed to determine traffic volume. Then the parameter such as number of lanes, lane usage, channelization, percent grade, curb radii, approach angle and sight distance must also be determined in this study by observing different factors such as geometric condition, traffic condition and control condition.

Table 1: Vehicle Classification (Arahan Teknik Jalan 8/86 (1986)) [6].

\begin{tabular}{|c|c|}
\hline Class & Vehicle Classification \\
\hline 1 & Passenger cars, Taxi, Small vans \& Utilities (Light 2-Axles) \\
\hline 2 & Lorry, large van (Heavy vehicle with 2-axles) \\
\hline 3 & Lorry, large van (Heavy vehicles with 3 axles or more) \\
\hline 4 & Buses \\
\hline 5 & Motorcycles, Scooters \\
\hline
\end{tabular}


Data analysis is the method used to analyze the data. The data obtained will be analysed using aaSIDRA, capacity softwate which determines delay at the unsignalised T-Junction. The Akcelik and Associated Signalised and Unsignalised Intersection Design and Research Aid (aaSIDRA) software is used as an aid to design and evaluate the unsignalised intersection (fixed time/pre-timed and actuated), roundabouts, two-way stop sign control, all-way stop sign control and give-way(yield) signcontrol. (Akcelik 2000) [11]. In this study, analyses were also being carried out using HCM 2000 (Transportation Research Board, 2000) and MHCM 2006 (Highway Planning Unit, 2006).

\section{RESULTS AND DISCUSSIONS}

All the data are collected from two T-junctions which are located at Jalan Datuk Mohammad Musa into Jalan Desa Ilmu and Jalan Datuk Mohammad Musa into Jalan Kuap. The collected data were analysed using SIDRA Intersection software in order to determine the critical factors affecting levels of service of a junction that has been mentioned before. The data analysed are represented in table and bar chart. From the chart, the result was analysed to show whether the objective of this research is achievable.

From the literature review, there are four (4) factors that affect the Level of Service (LOS). Thus, a study was conducted by collecting data at two unsignalised T-junctions. One of the factors being considered in the sensitivity analysis is a critical gap. From the analysis, critical gap was concluded as the critical factors affecting the Level of Service of the junction for SIDRA Intersection based on several factors analysed. Figure 3 shows that the percentage of reduction versus critical gap for SIDRA intersection, HCM 2000 and MHCM. The graph shows that critical gap was the most sensitive factor for SIDRA intersection as compared to HCM 2000 and MHCM 2006. The lower the critical gap, the lower value of average control delay which results in better quality of the level of service.

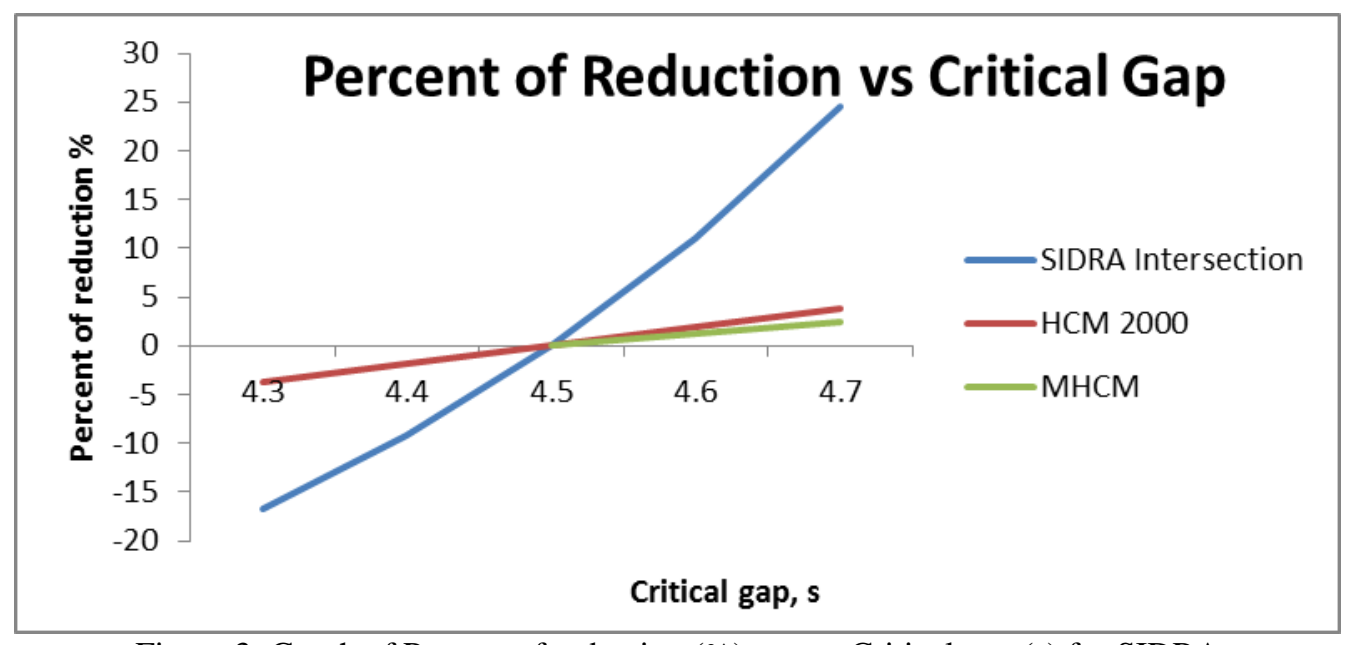

Figure 3: Graph of Percent of reduction (\%) versus Critical gap (s) for SIDRA Intersection, HCM 2000 and MHCM

Apart from that, the number of vehicles also become one of the critical factors affecting Level of Service of the two junctions for SIDRA Intersection. As shown in Figure 4, the sensitivity analysis using aaSIDRA is very significant as the number of vehicles increased. For the HCM 2000 and MHCM 2006, there is not much difference in the analysis results with an increase in the number of vehicles.

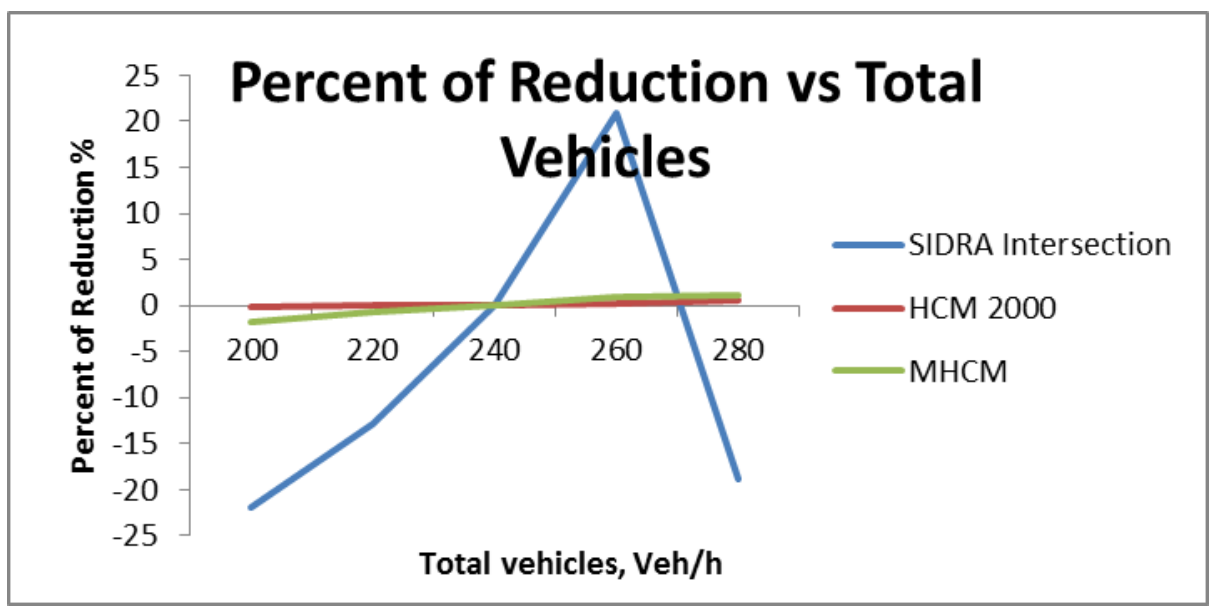

Figure 4: Graph of Percent of reduction (\%) versus Total Vehicles (Veh/h) for SIDRA 
From the analysis on Jalan Datuk Muhammad Musa into Jalan Desa Ilmu Junction and Jalan Datuk Muhammad Musa into Jalan Kuap Junction, the comparison of the outcome was apparent. Sensitivity analysis was evaluated for both intersections for several factors. A movement for an approach of an intersection was studied to determine the percentage of reduction of average control delay in order to determine which factors is the most influential in determining the level of service. Example of Delay and LOS at unsignalized T-Junction are as shown in Figure 5 and Figure 6.

Under critical gap, the average control delay value changes with the different critical gap were applied. It is observed that the higher the critical gap, the value of average control delay for the approach is highly too which will result in a lower level of service for the intersection. As for the follow-up time, as it increases, the average control delay will also increase for all the manual and software use in this analysis. For a proportion of heavy vehicles/motorcycles, the average control delay value can be determined and based on the analysis using the MHCM 2006, the higher the proportion of heavy vehicles/motorcycles, the lower the average control delay value. In addition, four different values of total vehicles, as the number of vehicles increase, most of the manual shows that the average control delay will also increase.

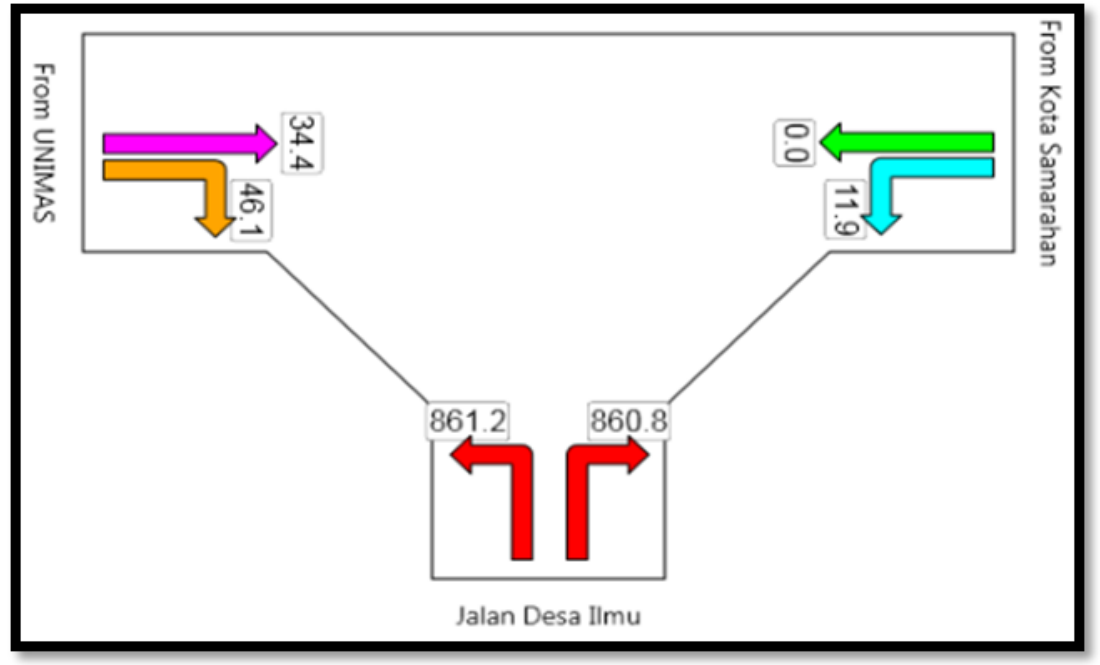

Figure 5: Delay at Unsignalised T-Junction (sec/veh)

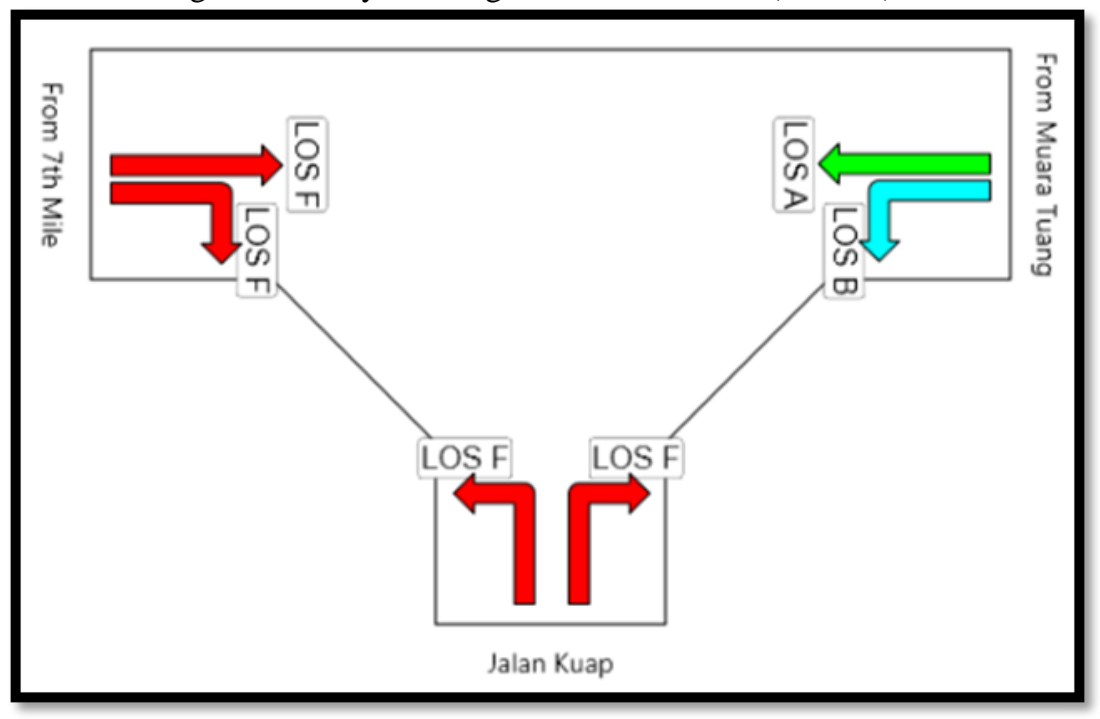

Figure 6: LOS at Unsignalised T-Junction

Based on the study on two different junctions, Jalan Datuk Muhammad Musa into Jalan Desa Ilmu Junction and Jalan Datuk Muhammad Musa into Jalan Kuap Junction, both junctions can be analysed using SIDRA Intersection, HCM 2000 and MHCM 2006 but produce different LOS where each way have their own method and standards to be followed. Both intersections were analysed under four different parameters which can affect the capacity of the intersection. Such parameters are critical gap, follow-up time, proportion of heavy vehicles or motorcycles and total vehicles. From the study, the critical factors affecting the level of service of a priority junction lies on these parameters. Level of service is determined by the average control delay which is a measure of the effectiveness of the level of service. With slight variations of the parameters, the value of average control delay is easily influenced thus results in the determination of the level of service for the intersection. 


\section{CONCLUSIONS}

In this study, sensitivity analysis of input parameters of the different traffic analysis methods were carried out. The parameters can vary, as long as it meets the standards and requirement from the manuals. Four parameters that had been analysed are critical gap, follow-up time, proportion of heavy vehicles or motorcycles and total volume of the vehicles. It is observed that with changes of values on any parameters, it will affect the average time delay on the output, thus affecting the Level of Service as well. Out of the four parameters it shows that critical factors affecting the LOS of the junctions is critical gap based on the percentage of the reduction in average control delay.

The analysis of critical factors affecting Level of Service at two unsignalised junctions, Jalan Datuk Muhammad Musa into Jalan Desa Ilmu and Jalan Datuk Muhammad Musa into Jalan Kuap was successfully completed. From the traffic volume study that was prepared manually using SIDRA Intersection and manual analysis, the main objectives of this study were able to be accomplished. It can be concluded that for unsignalised intersection that was analysed, different parameters contribute to different outcomes in Level of Service. These junctions performances of Level of Service is influenced by several factors of parameters such as critical gap, follow-up time, proportion of heavy vehicles/motorcycles, and traffic volume of vehicles.

From the analysis, critical gap and number of vehicles were concluded as the critical factors affecting the Level of Service of the junction for SIDRA Intersection based on several factors analysed. However, more factors can be analysed according to HCM and MHCM such as the existence of right turn lane, length of storage bay, approach speed and adjustment factor for each movement in order to determine the most critical factor affecting Level of Service thus the particular factor can be improved to better the quality of the Level of Service for unsignalised intersection or priority junction.

\section{REFERENCES}

[1] Carter, A.,Merritt, D., \& Robinson, C. (1982). Highway Capacity and Level of Services.Institute of Transportation Engineers. Transportation \& Traffic Engineering Handbook ( $2^{\text {nd }}$ ed). New Jersey : Prentice Hall; 500-514.

[2] Highway Planning Unit 2008, Malaysian Highway Capacity Manual. Ministry of Works, Malaysia.

[3] Malaysian Highway Capacity Manual 2006, Highway Planning Unit, Ministry of Works, Malaysia

[4] McShane, W. \& Roess, R. (1990). Traffic Engineering. New Jersey : Prentice Hall a. Pignataro, L. (1973). Traffic Engineering theory and practice. New Jersey : Prentice Hall

[5] Transport Research Board 2000, Highway Capacity Manual, Washington, D.C., USA.

[6] Arahan Teknik Jalan 11/87 (1987). A Guide to the Design of At-Grade Intersections. Jabatan Kerja Raya Malaysia.

[7] Arahan Teknik Jalan 8/86 (1986). A Guide to Geometric Design of Roads. Jabatan Kerja Raya Malaysia.

[8] Malaysian Highway Capacity Manual 2006. Unsignalised Intersections. Ministry of Work, Malaysia.

[9] HCM (1985). Special Report 209: Highway Capacity Manual, Transportation Research Board.

[10] McShane, W. R. and R.P. Roess. (1990). Traffic Engineering. Prentice Hall, a. Inc.,Englewood Cliffs, New Jersey

[11] Akcelik, R (2000); aaSIDRA User Guide; Akcelik and Associates Pty. Ltd 